\title{
Rupture of Unsacred Uterus in a Primipara (A Case Report)
}

\author{
Hisham Hussein Imam* \\ Department of Obstetrics \& Gynecology, Minia University, Egypt \\ Received: January 02, 2018; Published: January 17, 2018 \\ *Corresponding author: : Hisham Hussein Imam, Professor of Obstetrics \& Gynecology, Minia University, Egypt
}

Keywords: Unscarred uterus; Post-partum hemorrhage; Uterine rupture; Massive maternal hemorrhage; Uterine repair

Abbreviations: RBCs= Red Blood Cells, IV= IntraVenous, $\mathrm{OR}=0$ Operating Theater, $\mathrm{p} / \mathrm{m}=$ Pulse Per Minute, ICU= Intensive Care Unit, ${ }^{\circ} \mathrm{C}=\mathrm{Degree}$ Celsius, BP= Blood Pressure, HR= Heart Rate, gm/dl= Gram Per Deciliter, ml= milliliter

\section{Introduction}

A 31 years old lady gravid 2 para zero plus one with 39 weeks plus 5 days gestation came to labor and delivery room complaining of lower abdominal pain. She reported that her menstrual cycles were regular before pregnancy. Her obstetric history revealed a previous one complete abortion in first trimester not followed by curettage. In her current pregnancy, she had threatened abortion at the first trimester to which she was prescribed oral progesterone supplementation and her second and third trimester were uneventful. When came to the labor and delivery room, she was vitally stable, abdominal examination revealed the uterus to be term and with clinically big baby with cephalic presentation. Cardiotoco graphic tracing was reactive and with mild uterine contractions. Per vagina examination revealed that the uterine cervix was 2 to 3 centimeters dilated, soft, 50 percent effaced and posterior and the fetal head was at minus 3 station. Bedside gravid uterus ultrasound was requested and revealed a single living fetus with cephalic presentation with estimated fetal weight of 3750 grams, placenta fundal and amniotic fluid to be clear and average in amount.

The findings were discussed with the lady and her husband and they choose to have a trial of vaginal delivery. She was admitted to the hospital and put under observation with monitoring until after 7 hour she had spontaneous rupture of amniotic membranes. Per vagina examination revealed a full dilated and fully effaced uterine cervix, the head was at station-1, the membranes were absent and with clear liquor draining.. Thirty minutes later, she had spontaneous vaginal delivery of an alive baby boy with Apgar score 9 and 10 with medio-lateral episiotomy. Placenta and membranes delivered completely. Postpartum hemorrhage was noted .Continuous uterine massage was done in dwelling urinary catheter inserted, blood sample was sent to the blood bank and two units of cross matched packed RBCs were requested and two adequate IV ports established together with the use of ecbolics. The uterus was found to be contracted but vaginal bleeding continued. Estimated blood lose at this stage was $600 \mathrm{ml}$ and the patient was vitally stable. The patient was shifted to OR for vaginal exploration.

Vaginal exploration revealed excessive uterine and vaginal bleeding with multiple vaginal lacerations and bilateral cervical tears extending to the lower uterine segment were noted. Rapid hemostatic sutures were taken in the vaginal and the accessible part of the uterine cervix and a compressing vaginal pack was inserted. A decision for immediate laparotomy was taken. Massive maternal hemorrhage was announced as the estimated vaginal blood lose together with the estimated blood collected in the peritoneal cavity as evaluated by bedside abdominal ultrasound exceeded $2500 \mathrm{ml}$. Blood bank was contacted to prepare 5 units of packed RBCs, 5 units of fresh frozen plasma and 5 units of concentrated platelets. At this stage the vitals of the patient were as follows: pulse: $145 \mathrm{p} / \mathrm{m}$, blood pressure $70 / 40 \mathrm{mmHg}$ and respiratory rate $26 / \mathrm{min}$. During laparotomy, extensive hemo-peritoneum revealed the presence of $2000 \mathrm{ml}$. the Uterus was lax, cervical lacerations extended to the lower uterine segment were noted but not involving a major blood vessel. Hemostatic sutures were taken. Bilateral uterine artery ligations performed, continuous uterine massage performed; uterus was noticed to be better as regard to atony (i.e. started to contract). Evacuation of blood collected in the peritoneal cavity was done, two wide bore drains inserted one in the anterior and one in the posterior cul-de-sac; abdomen closed and patient wash hemostatically better and was shifted to ICU.

Five units of packed RBCs, 4 units of fresh frozen plasma and prophylactic antibiotic were transfused during the laparotomy. On arrival to the ICU, Patient was under effect of anesthesia, intubated, looks pale, marked peripheral cyanosis, hypothermic 
$36.6^{\circ} \mathrm{C}$, mild peripheral edema, with adequate urine output but un recordable peripheral BP, HR was 138/min and SPO2 100\%.Patient was connected to mechanical ventilator, with Oxytocin infusion, electrolyte imbalance corrected and analgesics given. Hemoglobin was $11 \mathrm{gm} / \mathrm{dl}$. Repeat after 6 hours and was found to be $6.8 \mathrm{gm} / \mathrm{dl}$, 2 units of packed RBCs were transfused and bedside abdominopelvic ultrasound was done and revealed a very minimal free intra peritoneal fluid seen in the pelvis. The patient was extubated after another 6 hours both abdominal drains were collecting $250 \mathrm{ml}$. The previously inserted compressing vaginal pack was removed and with minimal vaginal oozing noticed. On the second postoperative day, she was vitally stable, abdomen soft, slightly distended, sluggish bowel sounds, wound dressing done.

Abdominal drains collecting a total of $300 \mathrm{ml}$ of clear serous fluid. Patient blood hemoglobin was $8.8 \mathrm{gm} / \mathrm{dl}$ Sibs of water was given to her and she was put on prophylactic anticoagulant. On the third post-operative day she was doing fine and shifted to the regular ward. Her bowels were opened, drains collecting $200 \mathrm{ml}$ of clear serous fluid, Her blood hemoglobin was $9.2 \mathrm{gm} / \mathrm{dl}$. On the fourth post-operative day, she was vitally stable drains collecting only $100 \mathrm{ml}$ of clear serous fluid and were removed. On the fifth post-operative day, she was fine and discharged home and advised to come to the OPD for follow up.

\section{Discussion}

Rupture of the uterus during labor is a real catastrophe. It has very high maternal and fetal mortalities. This rupture usually affects scared uteri specially after intramural myomectomies and caesarian sections, However, unsacred uteri also may rupture and although rupture of unsacred uterus is rare, yet, it does occur [1]. In the past, there was a misconception that primiparus uterus in immune against rupture, but, this was proved to be incorrect [2]. Also, it was noticed that rupture of both scared and unscarred uteri has increased in the last decade [3]. In a large national population based cohort study conducted in Netherland, it was found that the incidences of rupture in unscarred and scared uteri were 0.7 and 5.1 per 10,000 deliveries [1]. Another study in the United State, reported that rupture of unscarred uterus occurs in 4.54 per $100,000[3]$.

Rupture of unscarred uterus may occur due to endogenous or exogenous causes. The endogenous causes include advanced maternal age and congenital disorders [4]. The exogenous causes may be accidental trauma like motor vehicle accidents or obstetric maneuvers like internal or external version [5]. We are reporting this patient because she seems to have relatively low risk factors as she did not have previous uterine surgeries, she is not that elderly (Age $=31$ years), there was no use of intra-partum uterotonic drugs, no instrumental delivery, no precipitate labor and the fetus was above average size (Fetal weight $3800 \mathrm{gm}$ ) but not macrosomic.

As regards to the decision of repairing the ruptured uterus or doing hysterectomy, this is of course should be dependent on many factors including the repairability of the ruptured site, the stability of the patient condition and the desire for future fertility. In this currently reported patient, reservation of the uterus was very important as the patient was primiparus and it was also feasible because of the repairability of the lacerations although at times the patient was vitally unstable. The risk of recurrent rupture should be considered as the data on future pregnancies after repair of a ruptured uterus are derived from small case series largely comprised of women who have undergone repair of a ruptured scared uterus.

The risks of recurrent rupture in the reported patients were ranging from 22 to 100 percent [6-8]. The risk of recurrent rupture was noticed to be highest when the uterine fundus was involved in the rupture [7]. A short inter-pregnancy interval following cesarean delivery appears to be associated with a higher risk of uterine rupture in women who attempt a trial of labor after a previous low transverse cesarean delivery. Extrapolating from these data, we suggest an inter-pregnancy interval of at least 18 to 24 months for women who desire pregnancy following repair of rupture of the unscarred uterus. Predicting scar rupture in a subsequent pregnancy is relatively difficult as there are no reliable predictive tests. Scar thickness and integrity may be assessed by ultrasound examination of previous caesarian section scars [9]. However, there are no similar studies testing the same for previous uterine rupture scars. Furthermore, women with normal lower uterine segment thickness antepartum have gone on to rupture their uterus when in labor [10].

The timing of delivery of the subsequent pregnancy should be determined cautiously as recurrent rupture may occur as early as the second trimester and is difficult to predict [6]. Most obstetricians attempt to reduce the risk of recurrent rupture by recommending cesarean delivery and scheduling the delivery before the onset of labor. There is no consensus on the optimum timing of delivery. If the prior rupture occurred in the fundus, one reasonable approach is to plan repeat cesarean after 36 completed weeks without amniocentesis, as neonatal outcomes are generally favorable at this gestational age and the risk of rupture increases with the onset of labor.

Another reasonable approach is to evaluate fetal pulmonary maturity by amniocentesis at 34 to 35 weeks and perform cesarean delivery upon confirmation of maturity. If test results are not consistent with pulmonary maturity, some obstetricians would give a course of antenatal corticosteroids and deliver the fetus 48 hours later, others would repeat testing in one week, and others would delay delivery until 37 weeks. Most experts suggest delivery by 37 weeks because morbidity in late preterm infants is low and considered acceptable when compared with the potential maternal and fetal consequences of recurrent rupture.

\section{References}

1. Zwart JJ, Richters JM, Ory F, de Vries JI, Bloemenkamp KW, et al. (2009) Uterine rupture in The Netherlands: a nationwide population-based cohort study. BJOG 116(8): 1069-1078.

2. Gibbins KJ, Weber T, Holmgren CM, Porter TF, Varner MW, et al. (2015) Maternal and fetal morbidity associated with uterine rupture of the unscarred uterus. Am J Obstet Gynecol 213(3): 382.e1-6. 
3. Al-Zirqi I, Stray-Pedersen B, Forsén L, Daltveit AK, Vangen S (2016) Uterine rupture: trends over 40 years. BJOG 123(5): 780-787.

4. Pepin M, Schwarze U, Superti-Furga A, Byers PH (2000) Clinical and genetic features of Ehlers-Danlos syndrome type IV, the vascular type. $\mathrm{N}$ Engl J Med 342(10): 673-680.

5. Walsh CA, Reardon W, Foley ME (2007) Unexplained prelabor uterine rupture in a term primigravida. Obstet Gynecol 108(3 Pt 2): 725-727.

6. Chibber R, El-Saleh E, Al Fadhli R, Al Jassar W, Al Harmi I (2010) Uterine rupture and subsequent pregnancy outcome--how safe is it ? A 25-year study. J Matern Fetal Neonatal Med 23(5): 421-424.

7. Usta IM, Hamdi MA, Musa AA, NassarAH (2007) Pregnancy outcome in patients with previous uterine rupture. ActaObstet Gynecol Scand 86(2): 172-176.
8. Lim AC, Kwee A, Bruinse HW (2005) Pregnancy after uterine rupture: a report of 5 cases and a review of the literature. Obstet Gynecol Surv 60(9): 613-617.

9. Jastrow N, Chaillet N, Roberge S, Morency AM, Lacasse Y, et al. (2010) Sonographic lower uterine segment thickness and risk of uterine scar defect: a systematic review. J Obstet Gynaecol Can 32(4): 321-327.

10. Cheung VY (2008) Sonographic measurement of the lower uterine segment thickness: is it truly predictive of uterine rupture? J Obstet Gynaecol Can 30(2): 148-151.

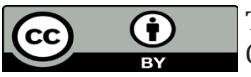

This work is licensed under Creative Commons Attribution 4.0 License

To Submit Your Article Click Here:

Submit Article

DOI: $10.32474 /$ OAJRSD.2018.01.000101

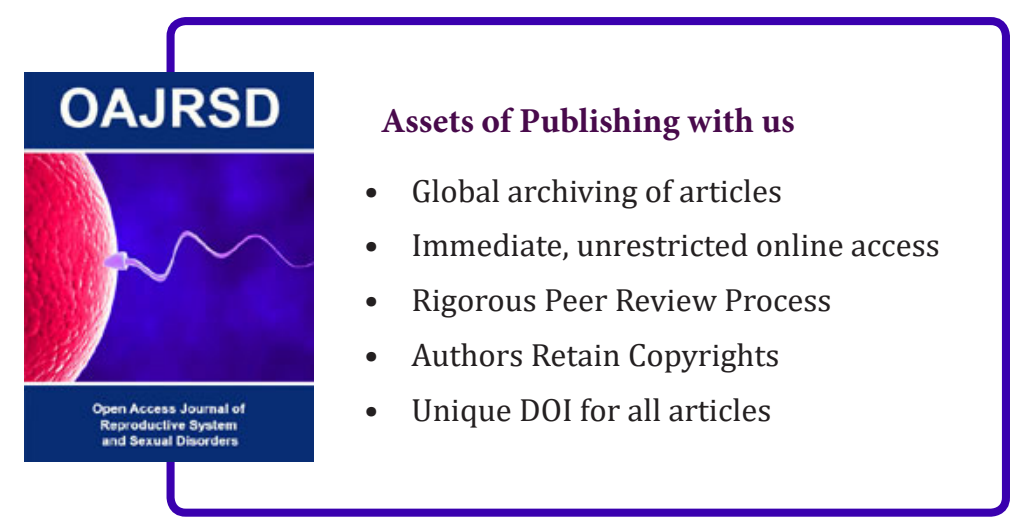

